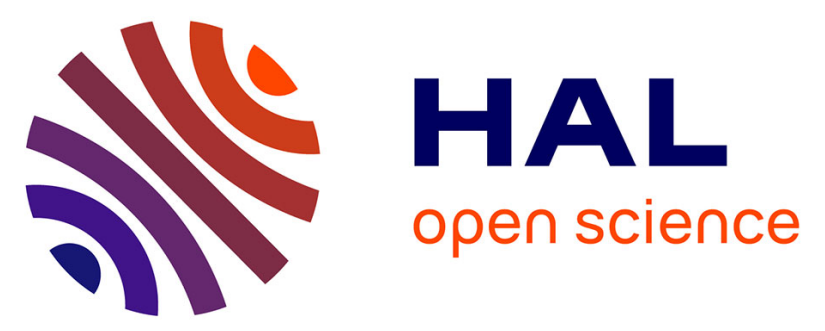

\title{
Effects of the temperature on the fatigue lifetime reinforcement of a filled NR
}

Benoît Ruellan, Jean-Benoit Le Cam, Eric Robin, Isabelle Jeanneau, F. Canévet, Frédéric Mortier

\section{- To cite this version:}

Benoît Ruellan, Jean-Benoit Le Cam, Eric Robin, Isabelle Jeanneau, F. Canévet, et al.. Effects of the temperature on the fatigue lifetime reinforcement of a filled NR. 11th European Conference on Constitutive Models for Rubber, Jun 2019, Nantes, France. pp.385-389, 10.1201/9780429324710-67 . hal-02499969

HAL Id: hal-02499969

https://hal-univ-rennes1.archives-ouvertes.fr/hal-02499969

Submitted on 24 Sep 2020

HAL is a multi-disciplinary open access archive for the deposit and dissemination of scientific research documents, whether they are published or not. The documents may come from teaching and research institutions in France or abroad, or from public or private research centers.
L'archive ouverte pluridisciplinaire HAL, est destinée au dépôt et à la diffusion de documents scientifiques de niveau recherche, publiés ou non, émanant des établissements d'enseignement et de recherche français ou étrangers, des laboratoires publics ou privés.

\section{(c)(1)}

Distributed under a Creative Commons Attribution| 4.0 International License 


\title{
Effects of the temperature on the fatigue lifetime reinforcement of a filled NR
}

\author{
B. Ruellan ${ }^{\star} \ddagger$ J.-B. Le Cam* E. Robin ${ }^{\star} \ddagger$ I. Jeanneau* ${ }^{\star} \ddagger$ F. Canévet ${ }^{\dagger} \&$ F. Mortier ${ }^{\dagger}$ \\ * Univ Rennes, CNRS, IPR (Institut de Physique de Rennes) \\ UMR 6251, F-35000 Rennes, France \\ ${ }^{\dagger}$ LC-DRIME, Joint Research Laboratory, Cooper Standard - IPR \\ UMR 6251, Campus de Bealieau; Bt 10B, 35042 Rennes Cedex, France \\ $\ddagger$ Cooper Standard France \\ 194 route de Lorient, 35043 Rennes - France
}

\begin{abstract}
Natural rubber (NR) exhibits extraordinary physical properties. Among them, its remarkable fatigue resistance was reported by Cadwell et al. as soon as 1940 (Cadwell et al. 1940). In particular, they found that NR exhibits a strong lifetime reinforcement for non-relaxing loadings (i.e. for $\mathrm{R}>0$ ). Since it was not observed in the case of non-crystallizable rubbers, such reinforcement is generally attributed to straininduced crystallization (SIC). In automotive applications, NR is used in anti-vibratory systems subjected to high temperatures. Surprisingly, few studies investigated the effect of temperature on the fatigue properties of NR, and more particularly on the lifetime reinforcement (Bathias et al. 1998), while SIC is a highly thermosensitive phenomenon (Trabelsi et al. 2002). The present study aims therefore at investigating how temperature affects the fatigue life reinforcement due to SIC under non-relaxing loading conditions. Fatigue experiments are first carried out at $23^{\circ} \mathrm{C}$ for loading ratios ranging from -0.25 to 0.35 , before being compared to results obtained at $90^{\circ} \mathrm{C}$ and $110^{\circ} \mathrm{C}$ where the ability of NR to crystallize is reduced or cancelled. Fatigue damage has been analyzed at both the macro and the microscopic scales. As expected, the material exhibits a strong lifetime reinforcement at $23^{\circ} \mathrm{C}$ and the fracture surfaces are peopled with SIC markers (wrenchings (Le Cam et al. 2004), striations (Le Cam and Toussaint 2010, Ruellan et al. 2018) and cones (Ruellan et al. 2018)). Their distribution is different between relaxing and non-relaxing loadings. At $90^{\circ} \mathrm{C}$, the reinforcement still occurs, even though SIC markers disappear from the fracture surfaces. Finally, the lifetime reinforcement totally vanishes at $110^{\circ} \mathrm{C}$.
\end{abstract}

\section{INTRODUCTION}

Numerous studies investigated fatigue of elastomers at room temperature, especially in the case of the natural rubber (NR). Nevertheless, the methodologies used differed in terms of sample geometry, material tested and loading conditions applied. Volumetric samples were most of the time preferred since they are more representative of rubber parts: Cadwell et al. (1940) introduced cylindrical samples before Beatty (1964) defined a Diabolo-like geometry that will be used in the following as the reference one. In the case of multiaxial fatigue experiments, samples with lower radius of curvature were used. Concerning the end-oflife criterion applied, it differed from a study to another: $(i)$ the sample failure (Cadwell et al. 1940), (ii) the appearance of a crack of a given length at the sample surface (Svensson 1981, Saintier 2000, Le Cam 2005, Ostoja-Kuczynski 2005), (iii) a drop of a physical parameter to a critical value (Mars 2001, Neuhaus et al. 2017), (iv) the brutal decrease of the maximal reaction force (Ostoja-Kuczynski et al. 2003, Ruellan et al. 2018). All these differences in terms of experimental conditions highlighted in this brief overview makes difficult any comparison between studies (for further information, the reader can refer to the state of the art in reference (Ruellan et al. 2018)).

However, general comments on the fatigue behavior of elastomers can be drawn with respect to the loading condition and the temperature. The fatigue life of NR strongly depends on the mean stress. Indeed, a lifetime reinforcement is observed for positive loadings ratios. It was first reported in the pioneering work by Cadwell et al. (1940). As no such lifetime reinforcement was observed in the case of noncrystallizable rubber (Lindley 1974, Fielding 1943), the reinforcement was commonly attributed to straininduced crystallization (SIC). The fatigue properties of NR are also influenced by temperature since it affects its ability to crystallize under tension. In the 
case of static loadings, Treloar (1975) initially estimated that the crystallites would completely disappear between 75 and $100^{\circ} \mathrm{C}$. Later, the development of crystallinity measurements performed by WAXS enabled the determination of this threshold more accurately: $75^{\circ} \mathrm{C}$ (Bruening et al. 2015), $80^{\circ} \mathrm{C}$ (Albouy et al. 2005, Candau et al. 2015) or $100^{\circ} \mathrm{C}$ (Trabelsi et al. 2002), even for large strains. Considering fatigue loadings, several studies investigated the effect of temperature in the case of relaxing loadings (Cadwell et al. 1940, Beatty 1964, Neuhaus et al. 2017). Generally, a decrease in fatigue life was measured with the increase in temperature on plane samples (Duan et al. 2016) and Diabolos samples (Lu 1991, Neuhaus et al. 2017). Under non-relaxing loadings, where the lifetime reinforcement occurs at room temperature, Bathias et al. (1998) showed that the lifetime reinforcement was still present at $80^{\circ} \mathrm{C}$ but occurred for more important mean stress than at $23^{\circ} \mathrm{C}$. Therefore, the investigation of the fatigue behavior of NR under more exhaustive loading conditions and temperatures is required to bring additional information on the effect of temperature on the lifetime reinforcement. It should be noted that filled NR is subjected to a significant self-heating, which is all the more important in the case of volumetric samples. For example, $\mathrm{Lu}$ (1991) measured a difference of $50^{\circ} \mathrm{C}$ between the bulk and the surface of a Diabolo sample tested under fatigue loadings. Therefore, self-heating has also to be taken into account in the investigation of fatigue of NR. This brief overview highlighted the lack of studies investigating the effect of temperature on the lifetime reinforcement of NR due to SIC. The present study therefore addresses this topic. The next section gives the experimental setup, then the results are presented and discussed. Concluding remarks close the paper.

\section{EXPERIMENTAL SETUP}

\subsection{Material and sample geometry}

The material considered is a carbon black filled natural rubber (cis-1,4 polyisoprene) vulcanized with sulphur. Samples tested are Diabolo samples. All the details are provided in reference (Ruellan et al. 2018).

\subsection{Loading conditions}

The fatigue tests were performed with a uni-axial MTS Landmark equipped with a homemade experimental apparatus. This apparatus enables us to test simultaneously and independently eight Diabolo samples, which compensates the fatigue tests duration and the dispersion in the fatigue live.

The tests were performed under prescribed displacement. The corresponding local deformation was calculated by FEA at the sample surface in the median zone. In order to investigate the effect of temperature on the fatigue properties, a Servathin heating chamber was used and three temperatures were applied: 23,90 and $110^{\circ} \mathrm{C}$. A pyrometer tracked the temperature of a material point located in the Diabolo median surface. For that purpose, a second homemade system has been developed to provide the suitable kinematics to the pyrometer. The frequency was chosen in such a way that the global strain rate $\dot{\varepsilon}$ was kept constant, ranging between 1.8 and $2.4 \mathrm{~s}^{-1}$ for one test to another one in order to limit self-heating. In practice, the frequency ranged between 1 and $4 \mathrm{~Hz}$, depending on the strain amplitude. Five different loading ratios $\mathrm{R}_{\varepsilon}=\frac{\varepsilon_{\min }}{\varepsilon_{\max }}$ were used: $-0.25 ; 0 ; 0.125 ; 0.25$ and 0.35 . It should be noted that loading ratios inferior, equal and superior to zero correspond to tension-compression, repeated tension and tension-tension, respectively.

\subsection{End-of-life criterion}

Considering the crack initiation approach, a physical criterion based on the maximal reaction force evolution was chosen. Three regimes were obtained during the fatigue test: the softening corresponding to a decrease in the maximal reaction force, its stabilization and its drop (brutal or not, depending on the loading and the environmental conditions). The number of cycles at crack initiation is denoted $\mathrm{N}_{i}$. It stands for the number of cycles at the end of the plateau, when the derivative of $\mathrm{F}_{\max }$ is no longer constant. In practice, it corresponds to the occurrence of a macroscopic crack whose length is at the most $5 \mathrm{~mm}$ at the sample surface.

\subsection{Scanning Electron Microscopy}

Fracture surfaces were observed with a JSM JEOL $7100 \mathrm{~F}$ scanning electron microscope (SEM). In addition, the SEM is coupled with an Oxford Instrument X Max Energy Dispersive Spectrometer of Xrays (EDS) and an Aztzec software in order to determine the surface fracture composition, especially in the crack initiation zone. The fracture surfaces to be analyzed were previously metallized by vapour deposition of an Au-Pd layer.

\section{RESULTS}

As the reference, results are first presented for fatigue tests carried out at $23^{\circ} \mathrm{C}$ in terms of fatigue life and damage mechanism. They are then compared to results obtained at 90 and $110^{\circ} \mathrm{C}$. Finally, a discussion on the effect of the temperature on the lifetime reinforcement is proposed.

\section{$3.123^{\circ} \mathrm{C}$}

The iso-lifetime curves are provided with respect to the loading conditions in the Haigh diagram presented 
in Figure 1. The black squares correspond to experimental fatigue tests defined according to the amplitude of force and the mean force applied. Even though the tests are prescribed in terms of displacement, the Haigh diagram is plotted in terms of force. Further discussion on the quantity to use for lifetime representation are given in Ruellan et al. (2018). Each square corresponds to a mean fatigue life value calculated from eight individual tests. In this diagram, the fatigue lifetimes range from $10^{4}$ to $10^{6}$ cycles, with $\mathrm{N}_{1}<\mathrm{N}_{2}$ $<\mathrm{N}_{3}<\mathrm{N}_{4}$.

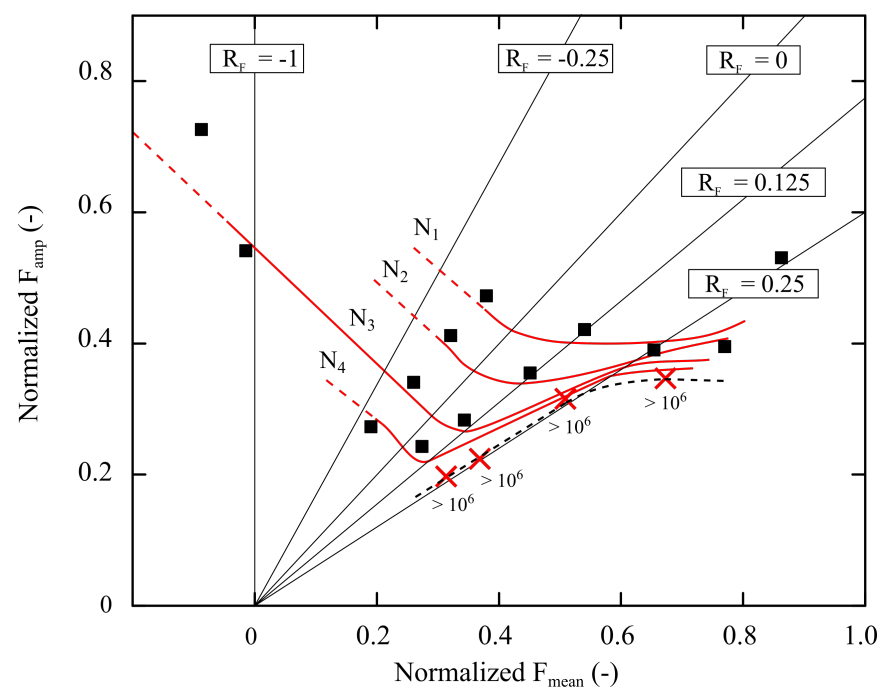

Figure 1. Haigh Diagram at $23^{\circ} \mathrm{C}$.

The fatigue life of the material at $23^{\circ} \mathrm{C}$ can be described with respect to the loading ratio:

- for tension-compression loadings $\left(-0.25<\mathrm{R}_{F}\right.$ $<0$ ), the iso-lifetime curves are decreasing monotonously. Therefore, it is concluded that the fatigue damage is driven by the maximum of loading,

- in the case of tension-tension loadings, the slope of the iso-lifetime curves increases in absolute value for loading ratios between $0<\mathrm{R}_{F}<0.125$. For $\mathbf{R}_{F}>0.125$, their slope becomes positive. For a given $\mathrm{F}_{a m p}$, an increase in $\mathrm{F}_{\text {mean }}$ increases the fatigue life, which illustrates the classical fatigue life reinforcement observed under nonrelaxing loadings. Note that for loading ratios $\mathbf{R}_{F}$ $>0.25$, the reinforcement is less pronounced.

Damage analysis performed at both the macro and the microscopic scales on the failure surface of Diabolo samples after fatigue failure put into light the strong effect of SIC on the damage mechanisms. In the reinforcement zone (i.e. for $\mathbf{R}_{F}>0$ ), wrenchings, fatigue striations and cones were observed. They are referred to as SIC markers in the following. This result confirms the role of SIC in the lifetime reinforcement process. More details on damage analysis are given in reference (Ruellan et al. 2018).

\section{$3.290^{\circ} \mathrm{C}$}

Fatigue life and damage mechanisms at $90^{\circ} \mathrm{C}$ differ from those obtained at $23^{\circ} \mathrm{C}$. Figure 2 presents the Haigh diagram obtained after fatigue experiments performed at $90^{\circ} \mathrm{C}$.

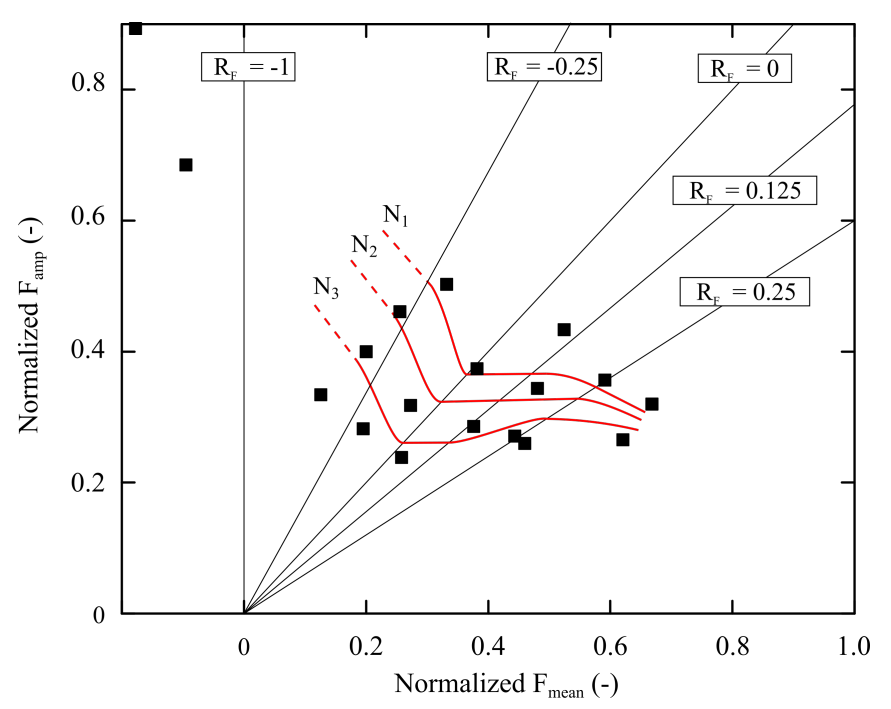

Figure 2. Haigh Diagram at $90^{\circ} \mathrm{C}$.

The results can be summed up as follows:

- for tension-compression loadings $\left(-0.25<\mathrm{R}_{F}\right.$ $<0$ ), the iso-fatigue lives are monotonously decreasing, as for $23^{\circ} \mathrm{C}$. However, it is to note that the fatigue lives for $\mathbf{R}_{F}=0$ loadings are inferior by a factor 2 to the ones measured at $23^{\circ} \mathrm{C}$. This result corroborates previous results in this field (Lake and Lindley 1964, Neuhaus et al. 2017),

- under tension-tension loadings, a slight lifetime reinforcement occurs for $-0.25<\mathrm{R}_{F}<0$ loadings since the slope of the iso-lifetime curves is positive. It is more important for the shortest lifetimes. Even though the reinforcement is less pronounced than at $23^{\circ} \mathrm{C}$, it does not disappear. This result can appear surprising since the crystallites are assumed to be melted at such temperature in the case of static loadings (Candau et al. 2015). For $\mathrm{R}_{F}>0.25$ loadings, the reinforcement decreases. This result was already observed by Cadwell et al. (1940) at $23^{\circ} \mathrm{C}$, for a sufficient mean loading. It could indicate that damage induced by the important maximal loading overcomes the reinforcing effect of SIC.

Damage analysis revealed the disappearance of SIC markers (wrenchings, striations and cones), while a lifetime reinforcement is still observed. Therefore it is concluded that SIC markers require a certain level of crystallinity to form.

\section{$3.3110^{\circ} \mathrm{C}$}

The Haigh diagram obtained at $110^{\circ} \mathrm{C}$ is presented in Figure 3. The iso-lifetime curves are monotonously 
decreasing with $\mathrm{F}_{\text {mean }}$. It indicates that $\mathrm{F}_{\text {max }}$ drives the fatigue life and that the reinforcement is lost. The damage mechanisms are similar to the ones observed at $90^{\circ} \mathrm{C}$.

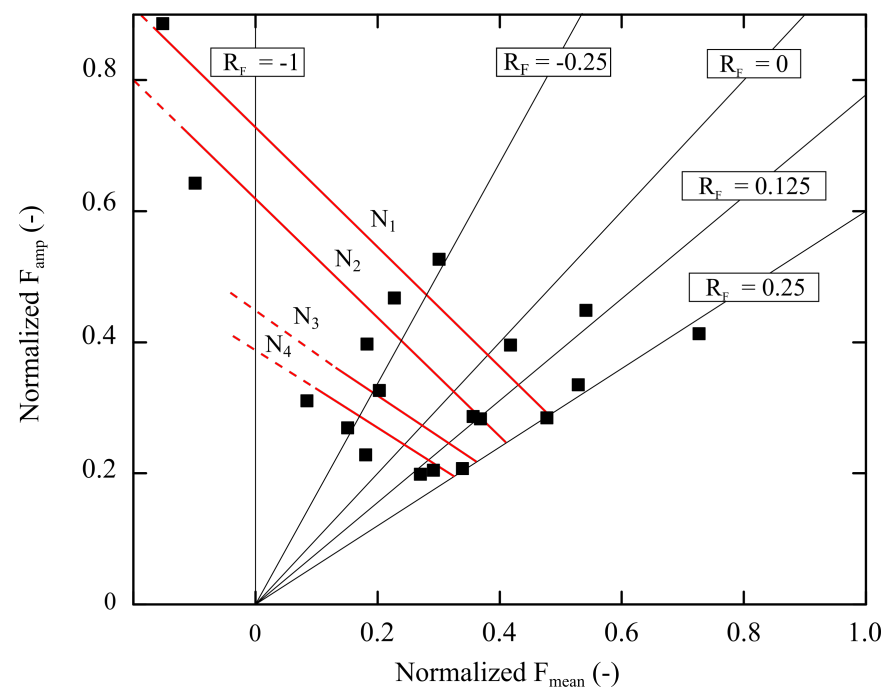

Figure 3. Haigh Diagram at $110^{\circ} \mathrm{C}$.

\section{DISCUSSION}

The fatigue behavior of NR is highly impacted by SIC, more particularly in the case of non-relaxing loadings. To put into perspective this phenomenon, a Haigh diagram is presented in Figure 4 and gives the iso-lifetimes for experiments performed at 23, 90 and $110^{\circ} \mathrm{C}$. For the sake of clarity, only two iso-lifetimes are represented per temperature.

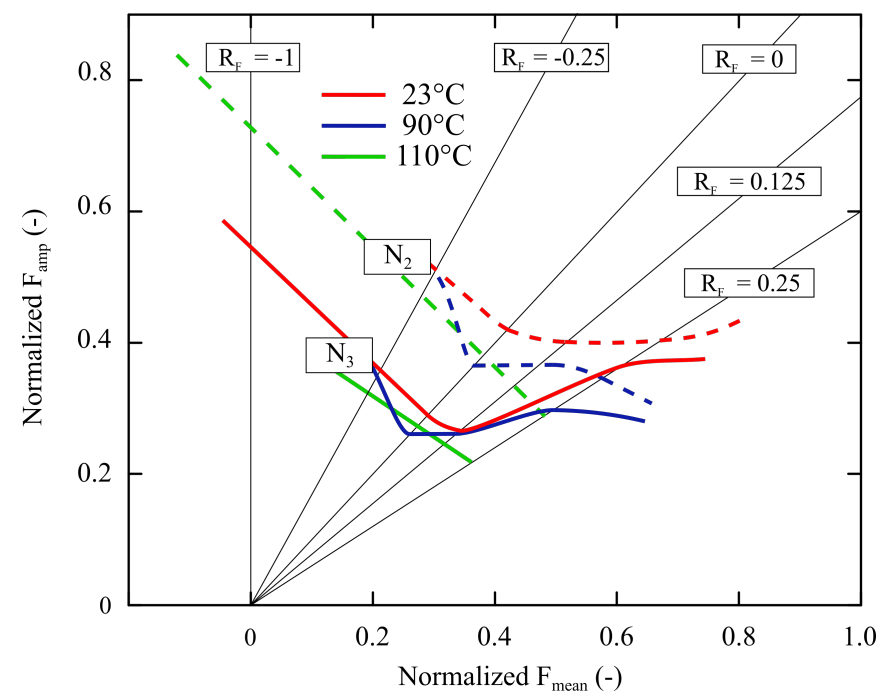

Figure 4. Haigh diagram at 23,90 and $110^{\circ} \mathrm{C}$ in red, blue and green, respectively.

At $23^{\circ} \mathrm{C}$, a strong lifetime reinforcement is measured and attributed to SIC. The presence of wrenchings, striations and cones on the Diabolo samples fracture surface testifies of the crystallization activation.

A less pronounced lifetime reinforcement was observed at $90^{\circ} \mathrm{C}$. However, the markers of SIC disappeared from the Diabolo samples fracture surface.
Since the crystallinity is assumed to be very small or equal to zero under static loadings, fatigue loadings appear therefore as a promoter of SIC. This was discussed in Beurrot-Borgarino et al. (2013). This result also means that even a small crystallinity value is sufficient to induce the fatigue reinforcement. Furthermore, the fact that no SIC marker forms at such temperature while a lifetime reinforcement is still observed could point out the existence of a crystallinity threshold in the formation of these markers. Our results differ from those presented in Bathias et al. (1998). Indeed, the authors measured a similar reinforcement at $80^{\circ} \mathrm{C}$ and at $23^{\circ} \mathrm{C}$, but occurring under a higher mean stress. Considering the Haigh diagram we obtained, this would have corresponded to a positive shift of the $\mathrm{F}_{\text {mean }}$ value at which the reinforcement is observed, which is not the case for the filled natural rubber we have tested. Of course, if the Haigh diagram is plotted in terms of displacement instead of force, the mean displacement at which the reinforcement is observed at $90^{\circ} \mathrm{C}$ increases. This is due to the fact that the loading is considered as nonrelaxing in terms of displacement, but the minimum force strongly decreases during the test at elevated temperature, becomes inferior to zero, and the reinforcement is lost. At $110^{\circ} \mathrm{C}$, the lifetime reinforcement vanishes and the material behaves as a non crystallizable rubber, as presumed by Lindley (1974).

\section{CONCLUSION}

This paper investigates the role of SIC in the lifetime reinforcement process of NR at different temperatures. Uni-axial fatigue experiments are carried out under loading ratios ranging from -0.25 to 0.35 at both room and elevated temperatures $\left(90\right.$ and $\left.110^{\circ} \mathrm{C}\right)$. The effect of the loading on the fatigue life is highlighted in the Haigh diagram and post-mortem analyses at both the micro and the macroscopic scales are used to better understand damage mechanisms. As expected, a strong lifetime reinforcement is observed at $23^{\circ} \mathrm{C}$ under positive loading ratios. At $90^{\circ} \mathrm{C}$, the reinforcement is less pronounced but is still observed. This suggests that fatigue loading is a SIC promoter and that only a small crystallite amount is required to activate the reinforcement. Finally, the lifetime reinforcement vanishes at $110^{\circ} \mathrm{C}$.

\section{ACKNOWLEDGEMENTS}

The authors thank the Cooper Standard France company for supporting this work and for fruitful discussions. The authors thank also the National Center for Scientific Research (MRCT-CNRS and MI-CNRS) and Rennes Metropole for supporting this work financially. SEM images were performed at CMEBA facility (ScanMAT, University of Rennes 1) which received a financial support from the European Union 


\section{REFERENCES}

Albouy, P. A., J. Marchal, and J. Rault (2005, Jul). Chain orientation in natural rubber, part $\mathrm{i}$ : The inverse yielding effect. The European Physical Journal E 17(3), 247-259.

Bathias, C., P. Houel, Y. N'Faly Berete, and K. Le Gorju (1998). Damage characterization of elastomeric composites using Xray attenuation. In K. L. Reifsnider, D. A. Dillard, and A. H. Cardon (Eds.), Fatigue and fracture, Volume Progress indurability analysis of composite systems: Third International Conference, 1997, pp. 103-110. Balkema.

Beatty, J. R. (1964). Fatigue of rubber. Rubber Chemistry and Technology 37, 1341-1364.

Beurrot-Borgarino, S., B. Huneau, E. Verron, and P. Rublon (2013). Strain-induced crystallization of carbon black-filled natural rubber during fatigue measured by in situ synchrotron $\mathrm{x}$-ray diffraction. International Journal of fatigue 47, 1-7.

Bruening, K., K. Schneider, S. V. Roth, and G. Heinrich (2015). Kinetics of strain-induced crystallization in natural rubber: A diffusion-controlled rate law. Polymer 72, 52 - 58 .

Cadwell, S. M., R. A. Merril, C. M. Sloman, and F. L. Yost (1940). Dynamic fatigue life of rubber. Industrial and Engineering Chemistry (reprinted in Rubber Chem. and Tech. 1940;13:304-315) 12, 19-23.

Candau, N., R. Laghmach, L. Chazeau, J.-M. Chenal, C. Gauthier, T. Biben, and E. Munch (2015). Temperature dependence of strain-induced crystallization in natural rubber: On the presence of different crystallite populations. Polymer 60 , $115-124$.

Duan, X., W.-B. Shangguan, M. Li, and S. Rakheja (2016). Measurement and modelling of the fatigue life of rubber mounts for an automotive powertrain at high temperatures. Proceedings of the Institution of Mechanical Engineers, Part D: Journal of Automobile Engineering 230(7), 942:954.

Fielding, J. H. (1943). Flex life and crystallisation of synthetic rubber. Industrial and Engineering Chemistry 35(12), 12591261.

Lake, G. J. and P. B. Lindley (1964). Cut growth and fatigue of rubbers. ii. experiments on a noncrystallizing rubber. Journal of Applied Polymer Science 8(2), 707-721.

Le Cam, J.-B. (2005, décembre). Endommagement en fatigue des elastomères. PhD thesis, École Centrale de Nantes.

Le Cam, J.-B., B. Huneau, E. Verron, and L. Gornet (2004). Mechanism of fatigue crack growth in carbon black filled natural rubber. Macromolecules 37, 5011-5017.

Le Cam, J.-B. and E. Toussaint (2010). The mechanism of fatigue crack growth in rubbers under severe loading: the effect of stress-induced crystallization. Macromolecules 43, 47084714.

Lindley, P. (1974). Non-relaxing crack growth and fatigue in a non-crystallizing rubber. Rubber Chemistry and Technology 47, 1253-1264.

Lu, C. (1991). Etude du comportement mécanique et des mécanismes d'endommagement des élastomères en fatigue et en fissuration par fatigue. $\mathrm{PhD}$ thesis, Conservatoire National des Arts et Métiers.

Mars, W. V. (2001). Multiaxial fatigue of rubber. PhD thesis. University of Toledo.

Neuhaus, C., A. Lion, M. Johlitz, P. Heuler, M. Barkhoff, and F. Duisen (2017). Fatigue behaviour of an elastomer under consideration of ageing effects. International Journal of $\mathrm{Fa}$ tigue 104(Supplement C), 72 - 80.

Ostoja-Kuczynski, E. (2005, Octobre). Comportement en fatigue des élastomères : application aux structures antivibratoires pour l'automobile. PhD thesis, École Centrale de Nantes.

Ostoja-Kuczynski, E., P. Charrier, E. Verron, G. Marckmann, L. Gornet, and G. Chagnon (2003, 15-17 September). Crack initiation in filled natural rubber: experimental database and macroscopic observations. In J. J. C. Busfield and A. Muhr (Eds.), Constitutive Models for Rubber III, pp. 310. Balkema.

Ruellan, B., J.-B. Le Cam, I. Jeanneau, F. Canévet, F. Mortier, and E. Robin (2018). Fatigue of natural rubber under different temperatures. International Journal of Fatigue. https://doi.org/10.1016/j.ijfatigue.2018.10.009.

Saintier, N. (2000). Prévisions de la durée de vie en fatigue du $N R$, sous chargement multiaxial. $\mathrm{PhD}$ thesis, École Nationale Supérieure des Mines de Paris.

Svensson, S. (1981). Testing methods for fatigue properties of rubber materials and vibration isolators. Polymer Testing 2, 161-174.

Trabelsi, S., P.-A. Albouy, and J. Rault (2002). Stress-induced crystallization around a crack tip in natural rubber. Macromolecules 35, 10054-10061.

Treloar, L. R. G. (1975). The Physics of Rubber Elasticity. Oxford: Oxford University Press. 